\title{
Effect of Silver Oxide Film Thickness on Some Optical Parameter
}

\author{
Israa H. Hilal* Waffaa K. Salman*
}

Zahrra H. HilaL**

Received 20, December, 2012

Accepted 11, March, 2014

\begin{abstract}
:
Films of silver oxide of different thickness have been prepared by the chemical spray paralysis. Transmission and absorption spectra have recorded in order to study the effect of increasing thickness on some optical parameter such as reflectance, refractive index, and dielectric constant in its two parts. This study reveals that all these paramters affect by increasing the thickness .
\end{abstract}

Key words: spray pyrolysis: $\mathrm{Ag}_{2} \mathrm{O}$ thin films; optical properties

\section{Introduction:}

Oxide silver is the material being used extensively in photography and in batteries with the chemical formula $\mathrm{Ag}_{2}$ O. It is consider commonly referred to as crstaline solid, as well as many other names, reflecting its widespread occurrence in nature and industry with and partial weight abut $(123.862 \mathrm{~g} / \mathrm{m})$, density $\left(0.01 \mathrm{~g} / \mathrm{cm}^{3}\right)[1]$. $\mathrm{Ag}_{2} \mathrm{O}$ is reported to be a - P/type semicondoctor [2] It considers from materials that can't analysis in water, [3]. The films that we obtain by chemical spray pyrolysis technique (CSPT) can be usful for the science used in the glass industry. Sapphire industrial uses lasers to produce intense light and is necessary for the production of high pressure sodium lampsand technical applications. This is a good economic ways to get on analyses and metals salts [4,5]. The target of this research is studying some optical properties for oxide silver and thickness effect on these properties in order to find the best thickness to obtain on the best properties .

\section{Materials and Methods:}

Experment
First : $\mathrm{AgNO}_{3}$ material is used for getting on oxide silver (0.1M). Depositionis used to obtain on a good film. It has been found that the following deposition parameters give good stoichiometric form surface

1.Substrate Temperature of about (400k).

2.Spray rate $30 \mathrm{sec} / 1 \mathrm{~min}$.

3. Air pressure $\left(2 \mathrm{~N} / \mathrm{m}^{2}\right)$.

4.Distance between sprayer nozzle and substrate of $28 \pm 1 \mathrm{~cm}$.

Preparing film are sprayed on borcilecat glass substrate after cleaning it and putting it on electrical heater about (30min) before spraying process so the glass substrate are nearly at the same temperature as the electric heater Each spraying period lasts for about $(15 \mathrm{sec})$ following spraying. The film were clear, transparent, gray to black colored having very good adhesve properties and are smooth surface free from pinholes by using weighting method and electronic balance (Metter AE-160) . The thickness of preparing films were in the range of $(12,25,90)$ $\mu \mathrm{m}$.

Second Optical measurements were concluded to record both 
spectrophotometer absorbance and Transmition for wavelength between (280-900) $\mathrm{nm}$ by using this type (PU/8800/UV/VIS Spectrophotometer) with two bands provided by philips company, using glass substrate like the glass that used for spraying as refrence. All measurements were made at room temperature .

\section{Results and Discussion}

Fig. 1 shows the relation between absorbance and photon energy, we found the behavior of curves is the same for each curves. The rapid increase of the a absorption in the high energy, this is refer to electronic transition, and this increase is continuous with the increase of photon energy , The effects of thickness, absorbance value increased with thickness increase and this agree with relation :

$$
\alpha=2.303 \mathrm{~A} / \mathrm{d}
$$

When : Absorption

$$
\begin{aligned}
& \mathrm{d}: \text { Thickness } \\
& \alpha: \text { Absorption coefficient }
\end{aligned}
$$

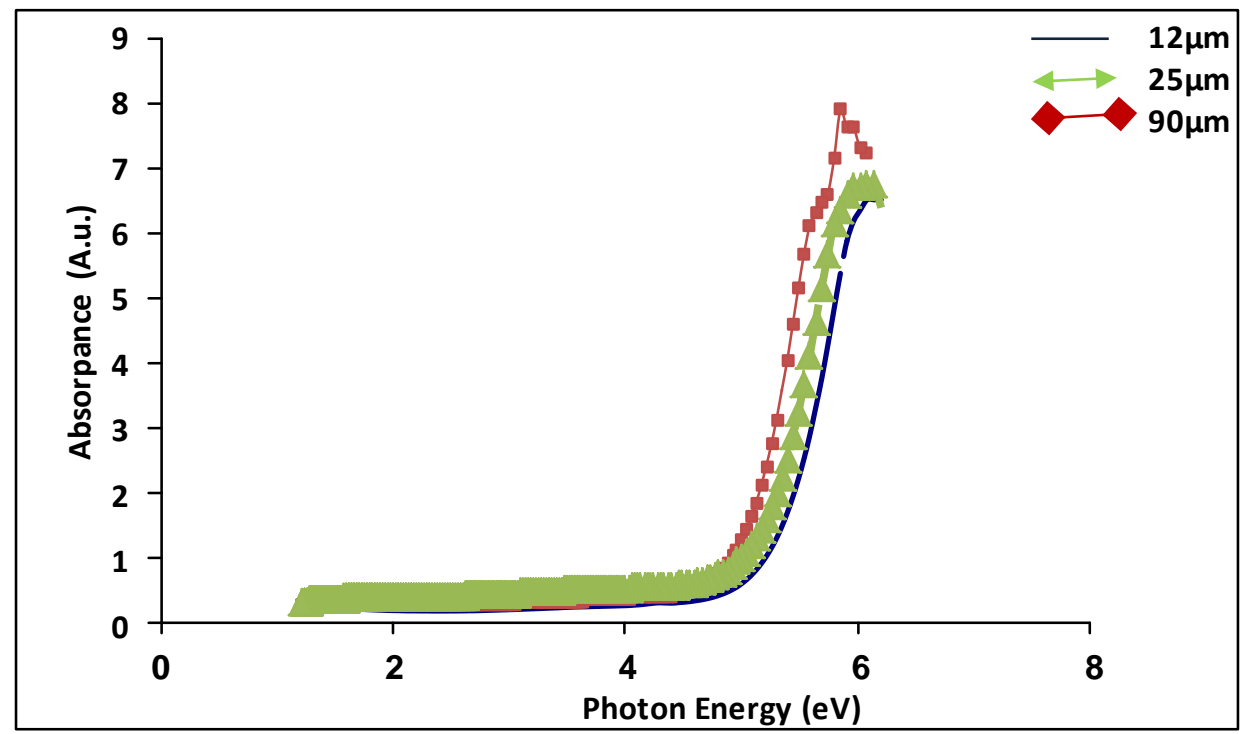

Fig. 1 Absorbance with photon energy

Fig. 2 shows the relation between transparence and photon energy, It was been found rapid decrease in low energies and sudden decrease in special energies and it continuous with increasing in high energy, thickness was increased refers to the decreaseing in transparent value

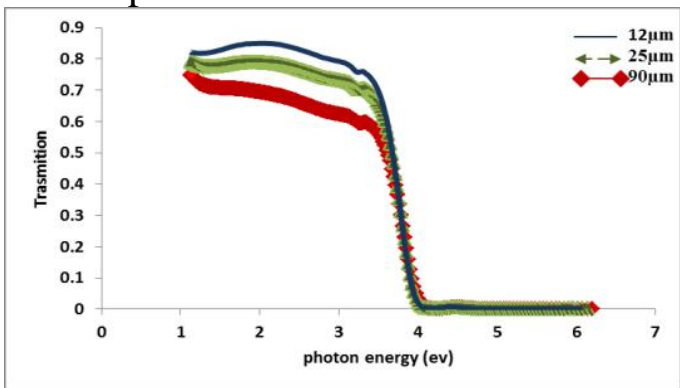

Fig. 2 Transparent with photon energy
The reflection were calculated depended on the concentration energy safe law using the relation: [6]

$$
\mathrm{R}+\mathrm{T}+\mathrm{A}=1
$$

When:

R:Reflection

$\mathrm{T}$ : Transmition

Fig. 3 shows the relation between reflection and photon energy . It had been found rapicl decrease in reflection value .until to arrive to peak, then it reduce from high energy because of less absorption in low energies from energy gap Transmition decreasing due to reflection increasing using the relation (2). At high energies from energy gap. The absorbance is 
increasing, this cause decreasing in reflection, the upper value (3 to 3.8 ) ev. Increasing of thickness due to minor change in the peak curves, it is shifted to low energies depending on conclusion absorption value in relation (1),optical $K_{0}$ coefficient was calculated using relation (3) [7]

$\mathrm{K}_{\mathrm{o}}=\alpha \lambda / 4 \pi$

Ko - Extinction coefficient

$\lambda$ - Wavelength

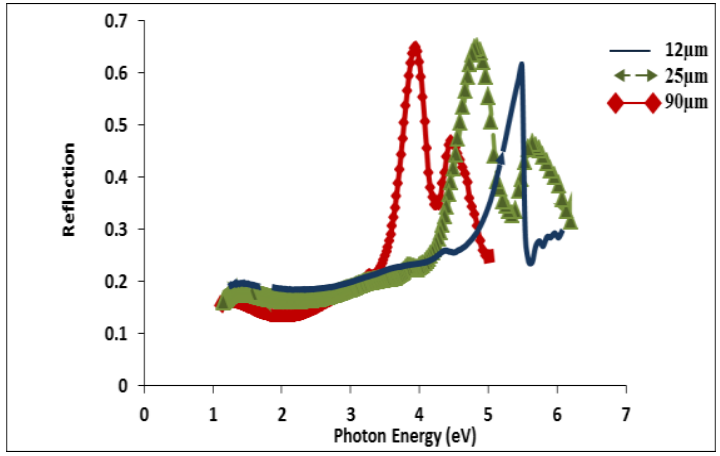

Fig. 3 Rreflection with photon energy

And the fig. 4 shows the relation between absorption coefficient and photon energy, at different thickness all curves have same behavior .

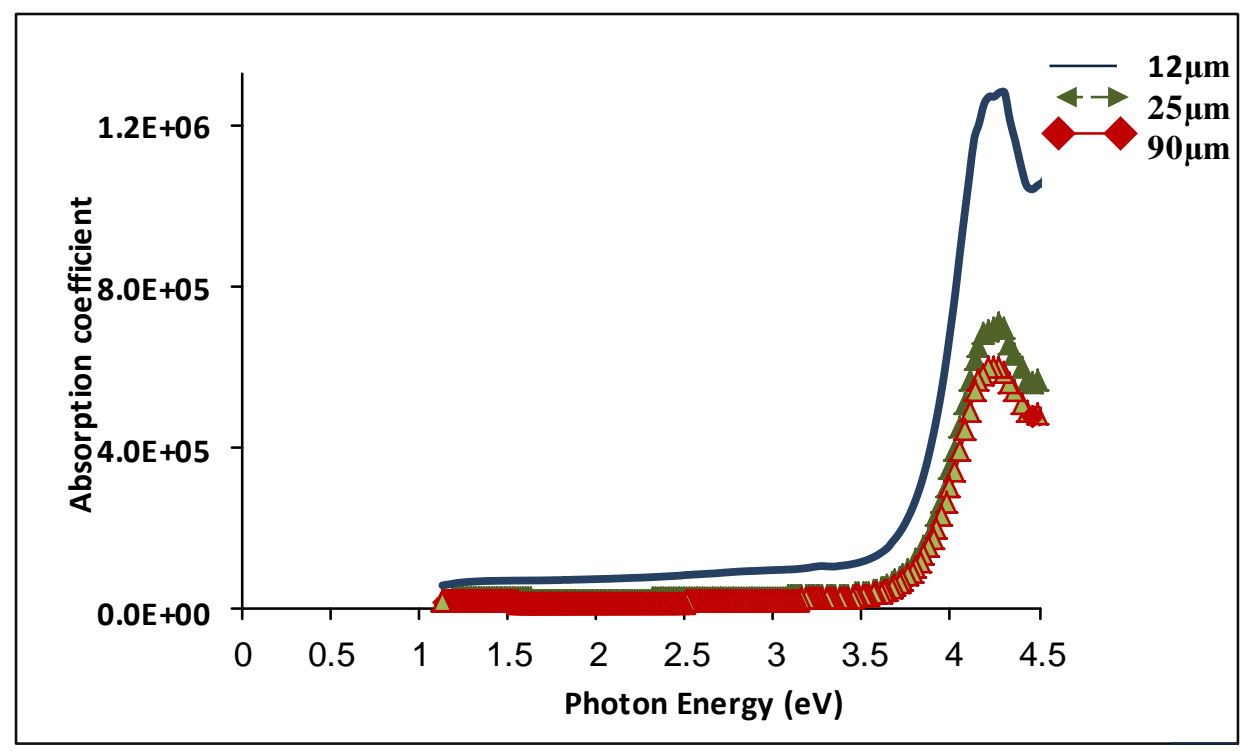

Fig. 4 Absorption coefficient with photon energy

The fig. 5 shows the relation between Reflective index and photon energy, during our showing to curves we notice that the behavior of curves is the same each samples. Reflective index is measured from the relation [8] Refraction index is descreasing with increasing of photon energy .Then it began to descrease, when curves peak shifted at low energy with increasing of thickness. This behavior is the same as reflective change with thickness according to a great connection between reflection and reflective index.

$\mathrm{n}_{\mathrm{o}}=\left\{\left(\frac{1+\mathrm{R}}{1-\mathrm{R}}\right)^{2}-\left(\mathrm{K}_{0}^{2}+1\right)\right\}^{1 / 2}+\frac{1+\mathrm{R}}{1-\mathrm{R}}$

$\mathrm{n}_{\mathrm{o}}$ Reflective index 


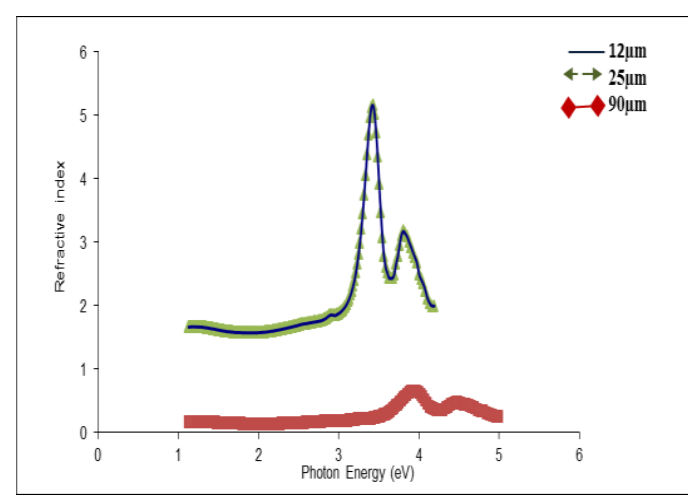

Fig. 5 Refractive index with photon energy

The dielectric constant real and imaginary part are measured according to these relations: $[9,10]$

$\varepsilon_{1}=\mathrm{n}_{0}-\mathrm{k}_{\mathrm{o}}$

$\varepsilon_{2}=2 \mathrm{n}_{0} \mathrm{k}_{\mathrm{o}}$

$\varepsilon_{1}$ - real part of dielectric constant

$\varepsilon_{2}$ - imaginary part of dielectric constant

Fig. 6 shows the relation between real part of dielectric constant and photon energy we were found refraction index curves. This result is depended on refractive index in relation (5) and we saw that the peak of curves is shifted to low energies with thin increasing .

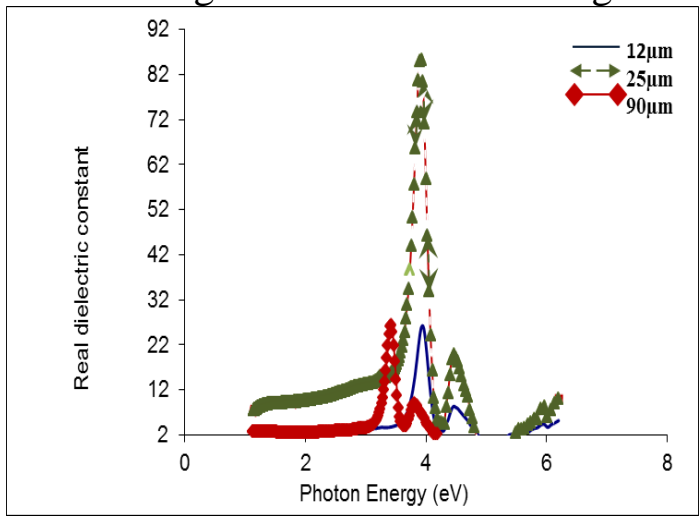

Fig.6 part real of dielectric constant with photon Energy

Fig. 7 shows the relation between imaginary part of dielectric constant and photon energy we were found the similarity between this relation and extinction coefficient curve because of it's in dependent on extinction coefficient with great degree as in relation (6) .

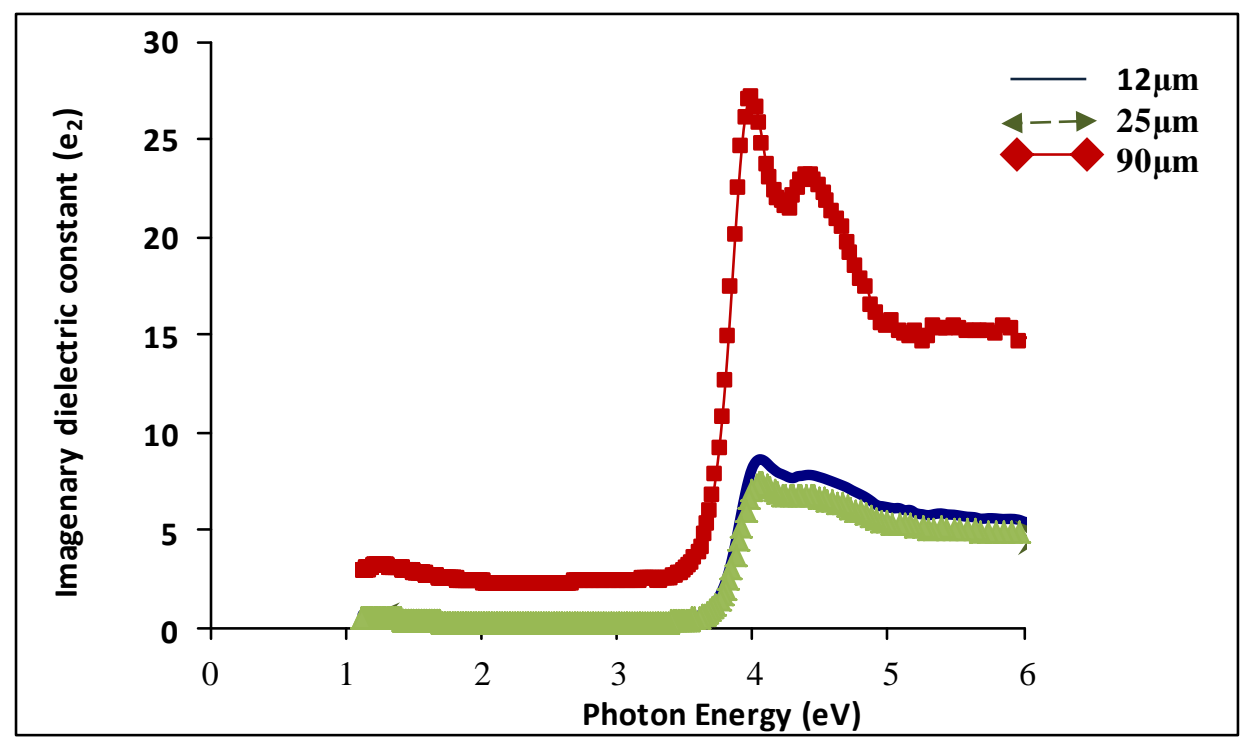

Fig.7 imaginary part of dielectric constant with photon energy

\section{Conclusion}

1. Absorption of the films are increased with increasing of the film's thickness .
2. Transparent of the films are increased with increasing of the film's thickness .

3. Peak shifted at low energy with increasing of the film's thickness . 


\section{References:}

1. Greenwood, Norman N. and Earnshaw, A. (1997)" Chemistry of the Elements, Oxford: ButterworthHeinemann " (2nd ed.)ISBN 0-75063365-4 p. 1181.

2. Yong, G.X., Liang, F.H. and Yuan , Z.Z. (2010) " Spectroscopic Ellipsometric Study of the Optical Properties of $\mathrm{Ag}_{2} \mathrm{O}$ Film Prepared by Direct Current Magnetron Reaction Sputtering " J.Chines phy., 19(9) :19. 3. Bark , U.K. and Subrahmanyam " A.S. (2000)" Proceeding of $11^{\text {th }}$ International Work Shop on Pysics of Semiconductor Devices " New Delhi India " Dec.11-14 : 1271.

4. Dakhel , A. (2008) "Correlated transport and optical phenomena in Ga- doped Cdo thin films " solar energy " 3(2):513 .

5. Ishiguro T. and Houri T.(2009) " Antireflection coating using aluminum hydroxide formed by hydrothermal treatment of sputtered aluminum films " Appl. Phys. " 106(23) : 524.
6. Ullash Kumar Barik, S.Srinivasan , C.L.Nagendra , A.Subrahmanyam. (2003) " Electrical and optical properties of reactive DC magnetron sputtered silver oxide thin films: role of oxygen " J. of Thin Solid Films " 1(429):129-134 .

7. Mullerova J. and Modron J. (2000)

" Determinantion of Optical Parameters and Thickness of Thin Films Deposited on Absorbing Substrates " Acta Physica Solvaca 50 ( 4) : 477 - 488 .

8. Dass H. and Habobi N . (1999) " Effects of Annealing on the Electronic Transitions of $\mathrm{ZnS}$ " J.College Education 4 (1) : 13.

9. Abrutis, J. A. ,Valincius G. , Baltrunas, G. (2007) " Spray Pyrolysis $\mathrm{Cd} 2 \mathrm{SnO} 4$

films for electrochemical applications " Thin Solid Films " 515 : 6817- 6823.

10. Vvedenskii , A. , et al. (2010) " The Influence of the Conditions of Anodic Formation and the Thickness of $\operatorname{Ag}(1)$ Oxide Nano Film on its Semiconductors Properties "J.Solid State Electrochem " 14 : 1401-1413.
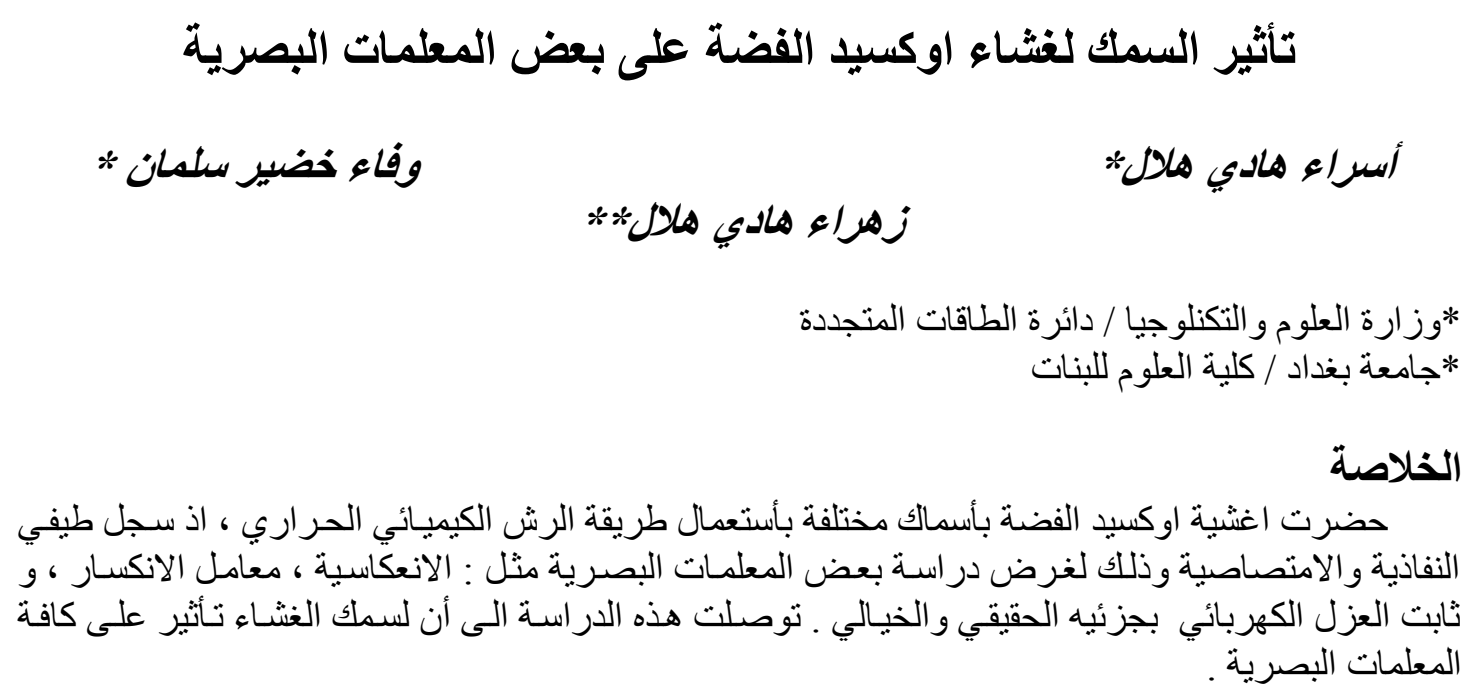